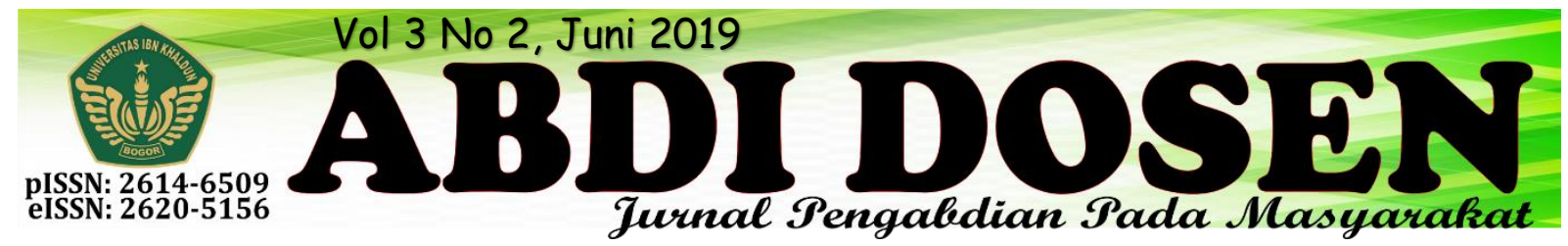

\title{
MENINGKATKAN KUALITAS SUMBER DAYA MANUSIA DI DESA CINANGKA MELALUI ASPEK PENDIDIKAN, SOSIAL DAN EKONOMI YANG DITUNJANG DENGAN PENGETAHUAN AGAMA DAN KESEHATAN JASMANI
}

\author{
Latifah Ratnawaty $^{1}$, Maudiawan Mubarak, Rasi Magi Akhsya ${ }^{2}$ \\ latifah@uika-bogor.ac.id \\ Fakultas Hukum Universitas Ibn Khaldun ${ }^{1}$, Mahasiswa KKN Kelompok 19 Tahun $2018^{2}$
}

\begin{abstract}
ABSTRAK
Pada program KKN kami merealisasikan salah satu tri dharma perguruan tinggi yaitu pemberdayaan masyarakat. Tujuan dari pelaksanaan program ini yaitu diharapkan mahasiswa memperoleh pengalaman belajar melalui keterlibatan dalam masyakarat yang secara langsung menemukan, merumuskan, memecahkan dan menanggulangi permasalahan yang berada di lapangan. Adapun khalayak sasaran dari pemberdayaan masyarakat yang kami lakukan yaitu siswa-siswi sekolah yang ada di kampung tersebut meliputi PAUD, SD, SMP, dan SMA. Banyak program yang kami laksanakan di kampung Cinangka tersebut. Program-program tersebut meliputi kegiatan belajar mengajar di sekolah, pelaksanaan kurikulum 2013, Learn and fun (Bahasa Inggris), Market Day, menabung sejak dini, penyuluhan kewirausahaan, pembuatan rambu-rambu tempat peribadatan, peringatan banyak anak-anak di sekitaran SDN Cinangka 04, rambu peringatan tikungan tajam, sosialisasi penerapan e-commerce pada pemuda setempat, penyuluhan dan praktik PHBD di sekolah dan posyandu, senam sore, pengajian ibu-ibu dan remaja putri desa Cinangka, mengajar Pendidikan Agama Islam, penyuluhan zakat, infaq dan sadaqah dan pelarangan riba di tingkat sd, baca tulis qur'an, rumah pintar, pelaksanaan lomba 17 Agustus, pemberian bibi pohon kepada desa Cinangka, perpisahan kampung dan perpisahan desa. Selama kurang lebih 1 bulan, program-program tersebut dapat terlaksana dengan baik dan dapat diterima oleh masyarakat.
\end{abstract}

\section{PENDAHULUAN}

Dalam pelaksanaan KKN Tematik Terintegrasi tahun 2018 ini kami sudah melaksanakan program yang sudah terencana dan tersusun selama masa KKN yang terdiri dari beberapa bidang, yaitu: Bidang Pendidikan, Bidang Ekonomi, Bidang Teknik, Bidang Kesehatan, Bidang Agama, dan Bidang Sosial. Selama megabdi kepada masyarakat setempat beberapa program telah kami laksanakan sesuai tujuan dan sasaran dan terlaksana dengan lancar.
Luas wilayah desa/kelurahan : $350 \mathrm{Ha} / \mathrm{km} 2$ Topografi wilayah desa/kelurahan:

a. Lereng/puncak $: 5 \%$

b. Lembah $: 10 \%$

c. Daratan :85\%

Penduduk dan keluarga

Jumlah kepala keluarga : : 4.065

Jumlah kepala keluarga perempuan : 528

Jumlah keluarga miskin $\quad: 1.422$

Jumlah penduduk laki-laki $\quad: 7.209$

Jumlah penduduk perempuan :7.019

Kepadatan penduduk $\quad: 41$ 
Jumlah kelahiran

Pengusaha

: 144 Jiwa

Jumlah penduduk berdasarkan mata

Pensiunan

: 192 Jiwa

pencaharian

Petani

: 960 Jiwa

Buruh industri

: 576 Jiwa

Buruh tani

: 1.200 Jiwa

PNS/ABRI

: 148 Jiwa

Angkutan

: 48 Jiwa

Pedagang

: 720 Jiwa

Lainnya

: 4.309 Jiwa

Buruh bangunan

: 240 Jiwa

\section{METODE PENGABDIAN}

Tahapan pelaksanaan untuk kegiatan ini sebagaimana terlihat pada bagan sebagai berikut:

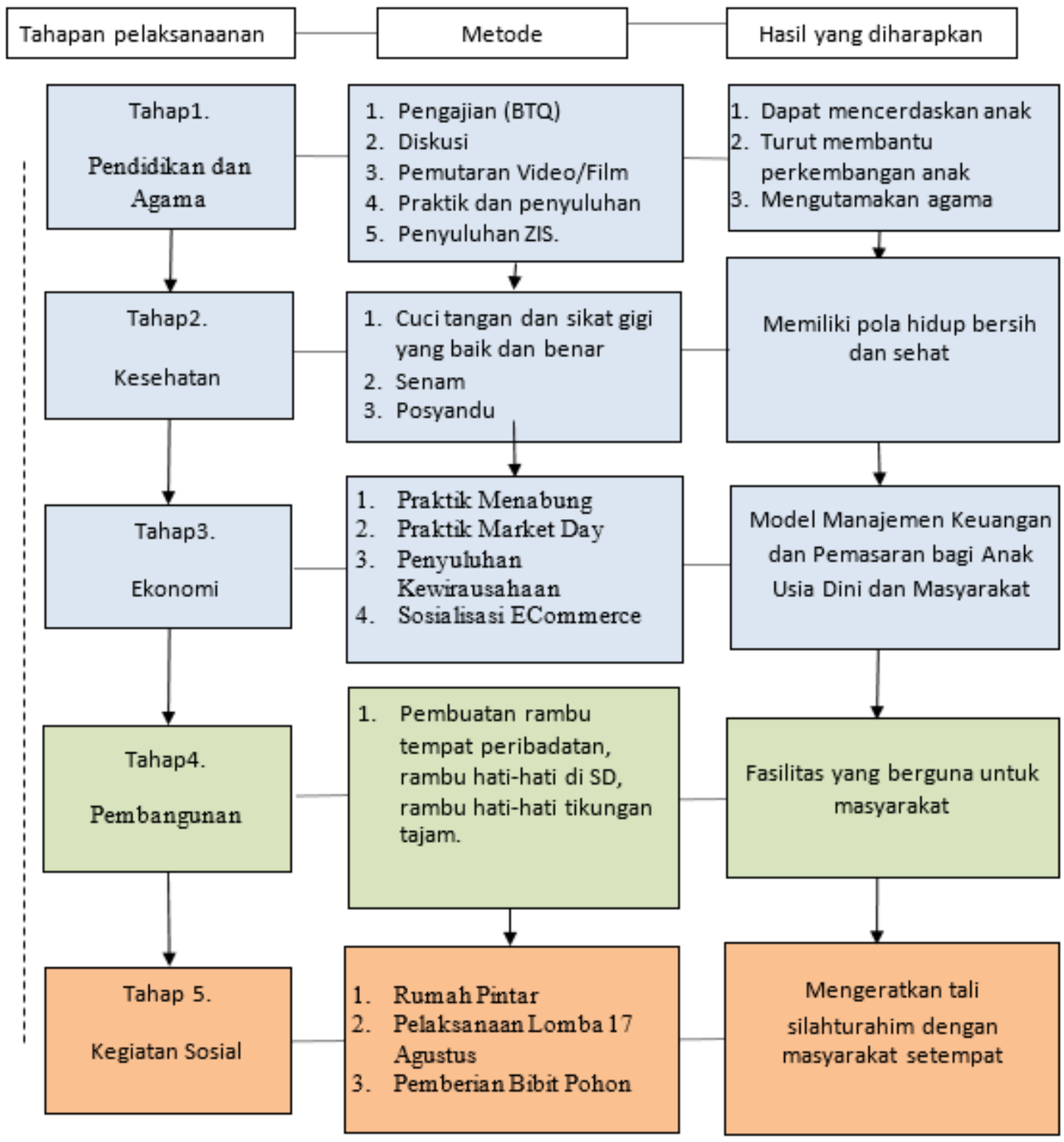


Jadwal Kegiatan

\begin{tabular}{|c|c|c|c|c|c|}
\hline \multirow{2}{*}{ No. } & \multirow{2}{*}{ Kegiatan } & \multicolumn{4}{|c|}{ Minggu } \\
\hline & & 1 & 2 & 3 & 4 \\
\hline 1 & Penyusunan Rencana kegiatan & & & & \\
\hline 2 & Sosialisasi rencana kegiatan & & & & \\
\hline 3 & Mengajar PAI Kelas IV dan BTQ & & & & \\
\hline 4 & Pelaksanaan Kurikulum 2013 (K-13) Kelas IV.B & & & & \\
\hline 5 & Penyuluhan dan Praktik PHBS (Mencuci Tangan dan Sikat Gigi) & & & & \\
\hline 6 & Pengajian Ibu-ibu & & & & \\
\hline 7 & Learn and Fun & & & & \\
\hline 8 & Sosialisasi ZIS (Zakat, Infak dan Shodakoh) & & & & \\
\hline 9 & Kegiatan PHBS (Senam) & & & & \\
\hline 10 & Praktik Market Day di Tingkat PAUD dan TK & & & & \\
\hline 11 & Lomba 17-an PAUD dan TK & & & & \\
\hline 12 & Kegiatan PHBS (Posyandu) & & & & \\
\hline 13 & Sosialisasi E-Commers dan Kewirausahaan & & & & \\
\hline 14 & Pembuatan Rambu dan Petunjuk Arah & & & & \\
\hline 15 & Rumah Pintar & & & & \\
\hline
\end{tabular}

\section{MetodePendekatan}

Pendekatan yang digunakan dalam kegiatan ini adalah:

1. Penggunaan pembelajaran kontekstual memiliki potensi tidak hanya untuk mengembangkan ranah pengetahuan dan keterampilan proses, tetapi juga untuk mengembangkan sikap, nilai, serta kreativitas siswa dalam memecahkan masalah yang terkait dengan kehidupan mereka sehari-hari melalui interaksi dengan sesama teman, misalnya melalui pembelajaran kooperatif, sehingga juga mengembangkan ketrampilan sosial (social skills) (Dirjen Dikmenum, 2002:6).

2. Pendekatan Induktif

Pendekatan induktif menekanan pada pengamatan dahulu, lalu menarik kesimpulan berdasarkan pengamatan tersebut. Metode ini sering disebut sebagai sebuah pendekatan pengambilan kesimpulan dari khusus menjadi umum.
3. Pendekatan Proses

Pendekatan proses merupakan pendekatan pengajaran yang memberikan kesempatan kepada siswa untuk menghayati proses penemuan atau penyusunan suatu konsep sebagai suatu keterampilan.

\section{Partisipasi Masyarakat}

dalam

\section{Pelaksanaan Program}

Partisipasi masyarakat yang dapat dilakukan dalam kegiatan ini adalah sebagai berikut:

1. Mempersiapkan dan mengerahkan warga Kp. Cinangka RW 03 untuk mengsukseskan Penyuluhan ECommerce dan Kewirausahaan.

2. Menyediakan dengan suka rela Majlis TK dan PAUD Bunga Bangsa untuk mengsukseskan Penyuluhan ECommerce dan Kewirausahaan.

3. Memberi izin dan mengerahkan anakanak usia dini Kp. Cinangka RW 03 untuk mengikuti kegiatan pembelajaran Rumah Pintar. 
4. Memfasilitasi tempat dan perlatan selama pembuatan rambu-rambu dikawasan Kp. Cinangka.

5. Turut membantu dan menyediakan peralatan saat pemasangan ramburambu dikawasan Kp. Cinangka.

\section{Langkah Evaluasi}

Evaluasi yang akan dilakukan terdiri dari:

1. Evaluasi proses, yang terkait dengan perencanaan dan pelaksanaan

\section{HASIL PROGRAM}

Pelaksanaan program kerja KKN 06 selama 1 bulan terhitung mulai tanggal 07 Agustus - 07 September 2018 di Kampung Sinar Wangi RT04/RW07 Desa Tapos Satu Kecamatan Tenjolaya Kabupaten
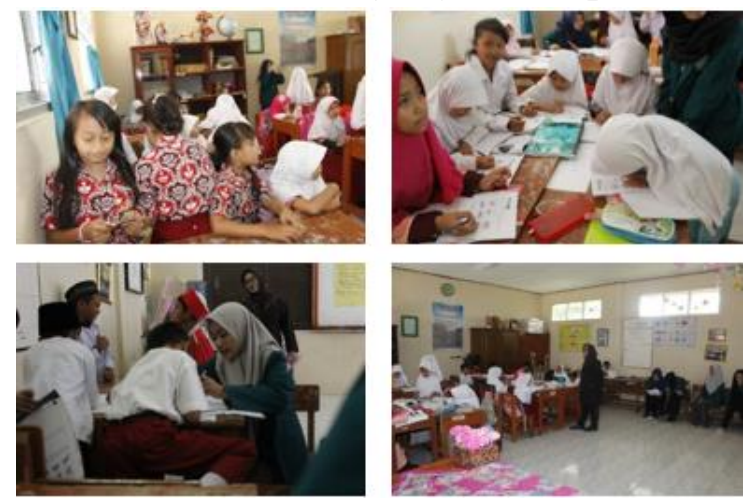

Pelaksanaan Kurikulum 2013
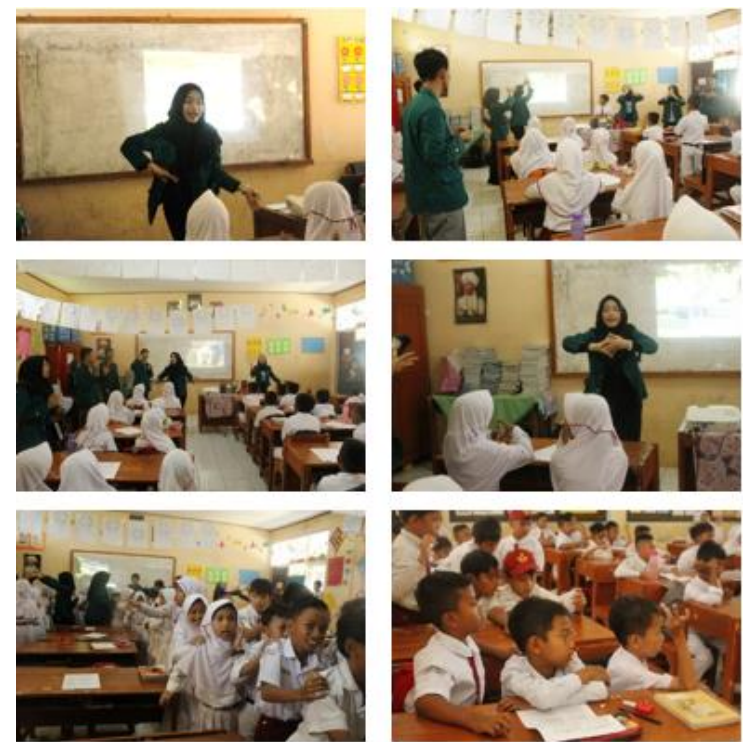

Learn and Fun kegiatan. Evaluasi proses akan dilakukan setiap harinya bersama para anggota KKN dan setiap hari tertentu berasama para warga dan petingginya (Ketua RW 03, RT 01-05, Kader Posyandu, dan Ketua Karang Taruna).

2. Evaluasi hasil, yang akan dilaksanakan setelah kegiatan dilaksanakan.

3. Evaluasi dampak, yang akan dilakukan
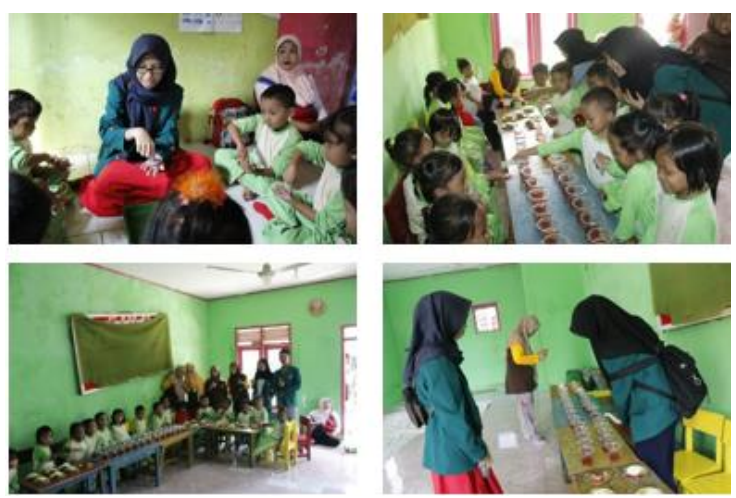

Praktik Market Day
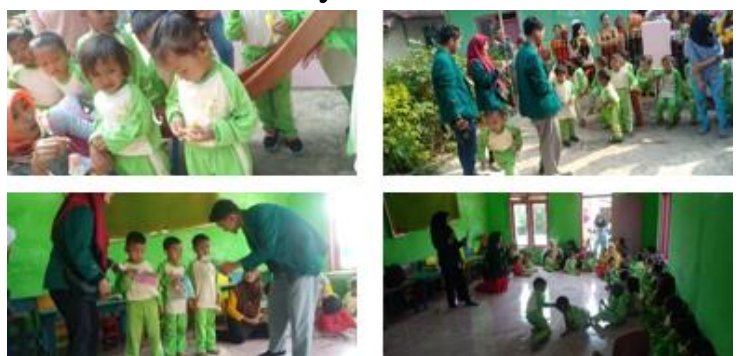

Praktik Menabung Sejak Dini 

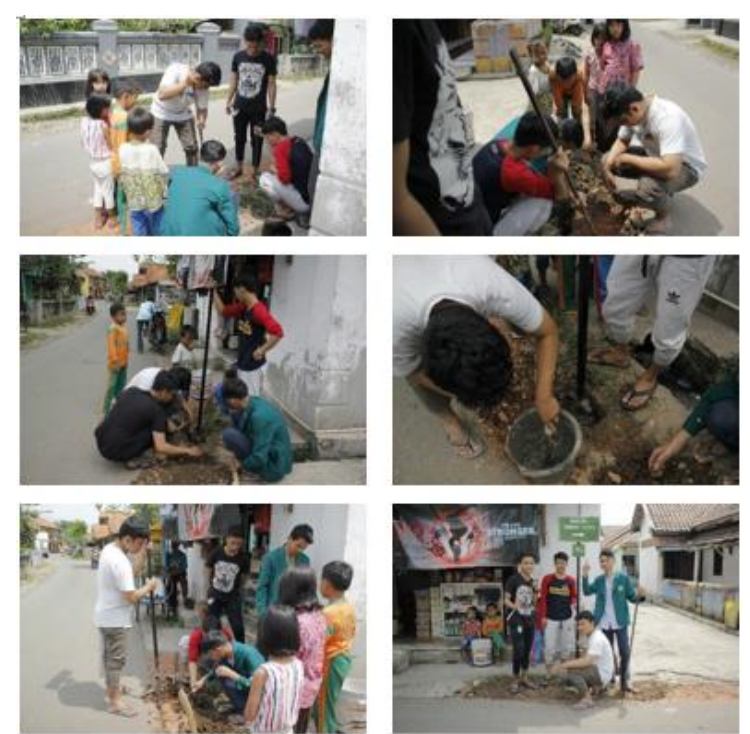

Pembuatan Rambu

Petunjuk tempat Peribadatan "Masjid Nurul Huda"
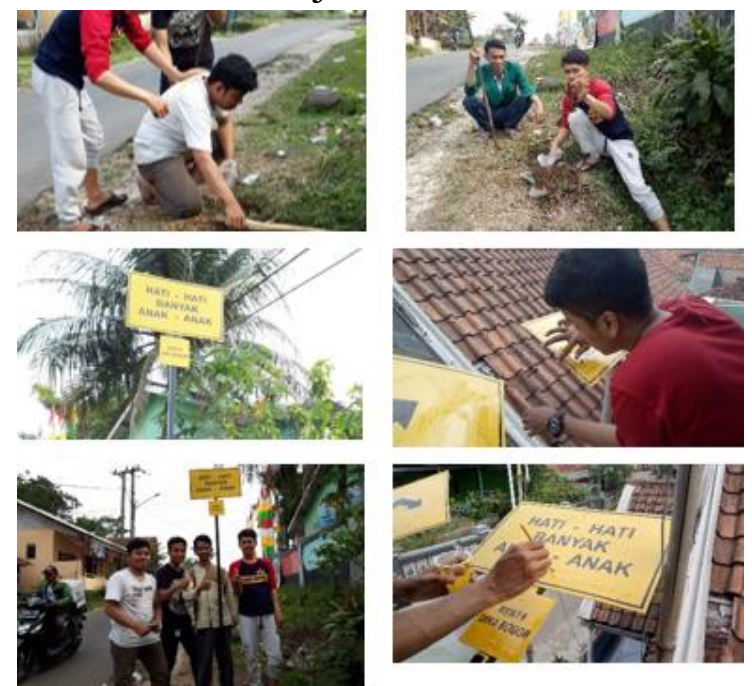

Pembuatan Rambu Peringatan "Hati-hati banyak anak-anak" di Depan SDN Cinangka 4
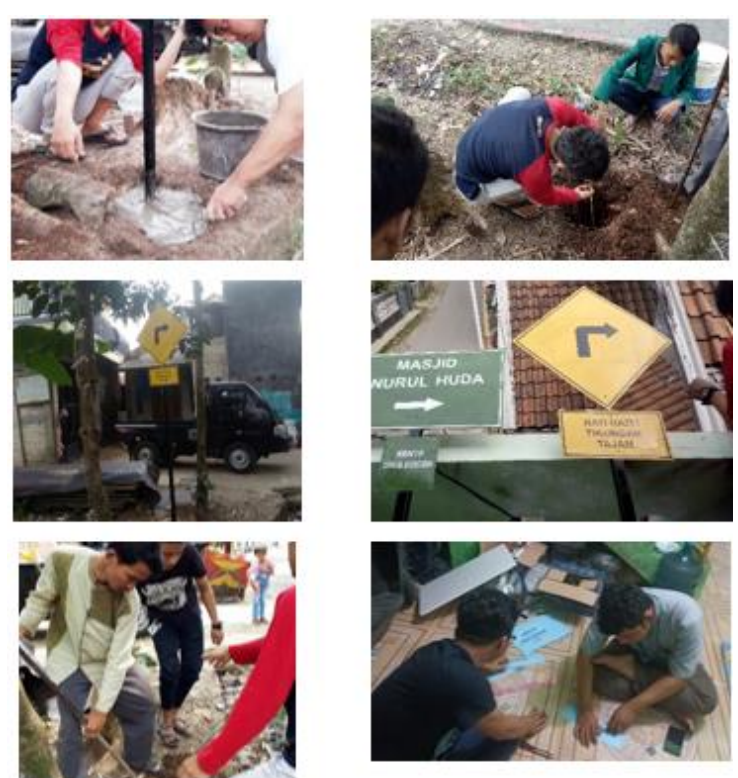

Pembuatan Rambu Peringatan "hati-hati tikungan tajam"
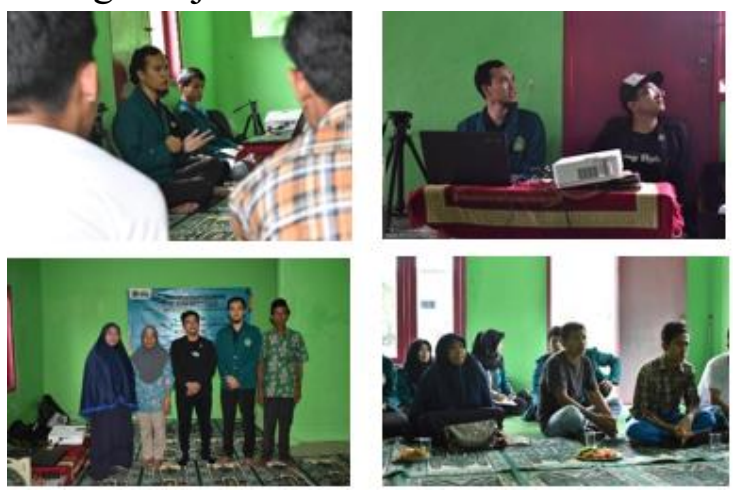

Sosialisasi penerapan E-Commerce pada Pemuda Setempat, Desa Cinangka
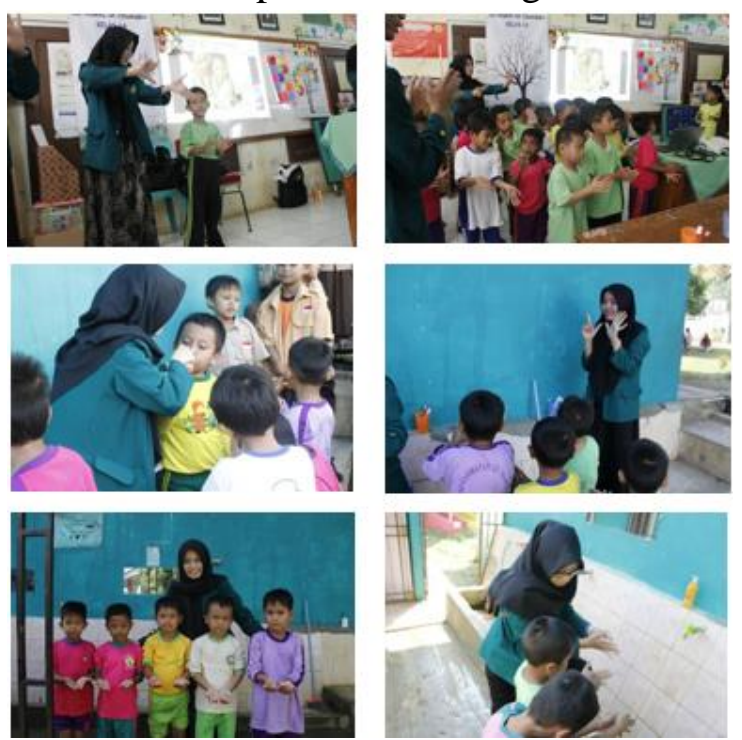

Penyuluhan dan praktik PHBS di desa Cinangka 

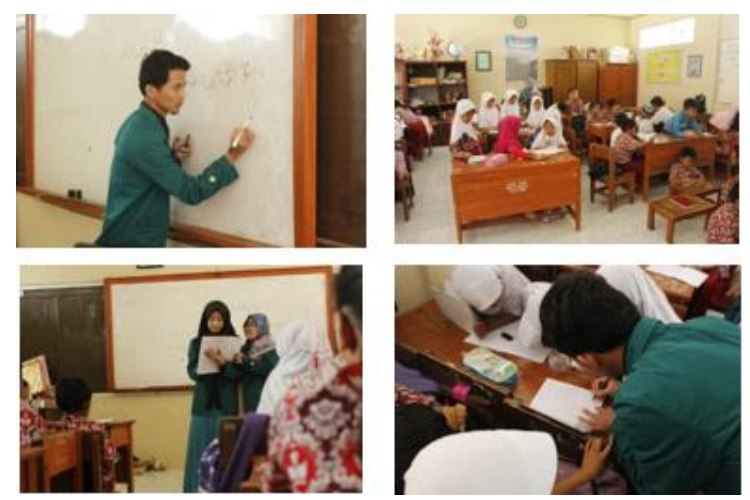

Mengajar PAI yang menyenangkan di SDN Cinangka 4
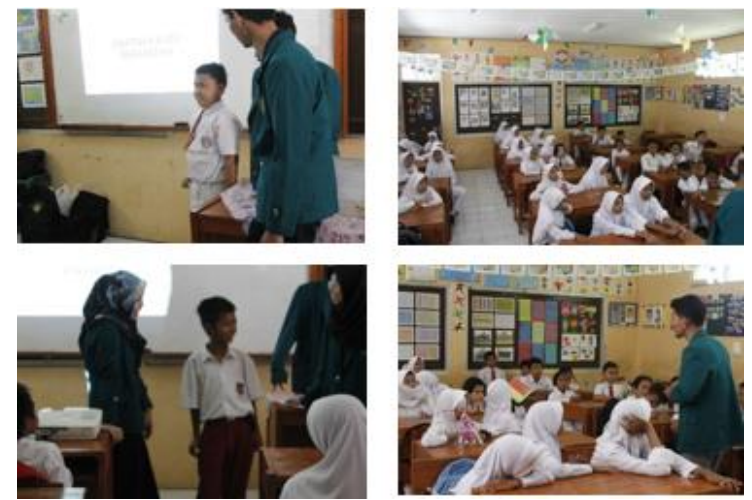

Penyuluhan ZIS dan pelarangan Riba ditingkat SD
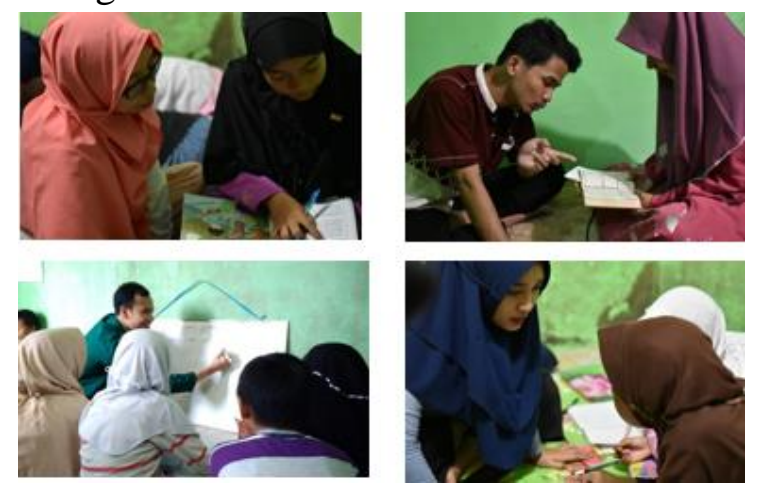

Rumah Pintar

\section{KESIMPULAN}

Pelaksanaan Kurikulum 2013 (K-13) di SDN Cinangka 04 Dengan dilaksanakannya kegiatan tersebut bertujuan untuk memaksimalkan guru dalam penggunaan kurikulum 2013 dengan Tema 1 (Indahnya Kebersamaan) dengan Subtema 1 serta Pembelajaran 5 dengan mata pelajaran IPS tentang keberagaman budaya di Indonesia yang meliputi Agama, suku, bahasa, kebiasaan dan lain-lain.
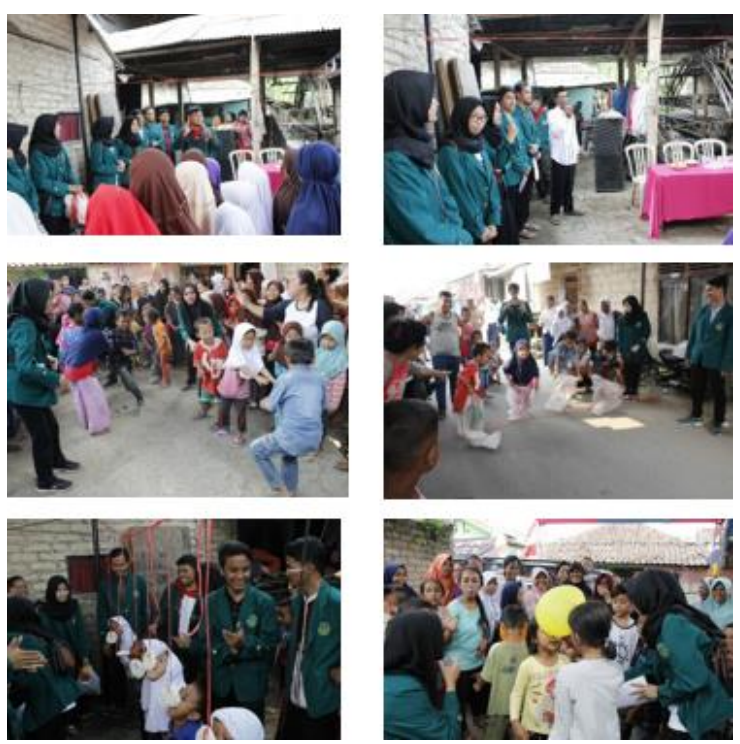

Pelaksanaan lomba 17 agustus di RT.02/03

Desa Cinangka
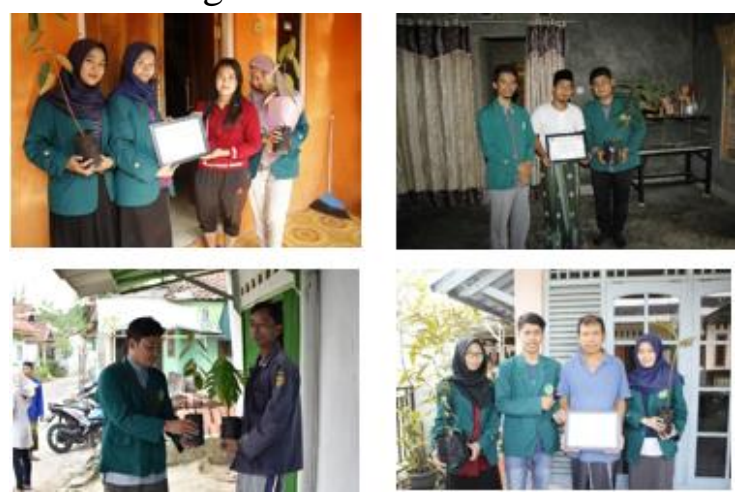

Pemberian Bibit Pohon Kepada RT di RW 03

Learn and Fun, sangat efektif dalam proses pembelajaran Bahasa Inggris dimana yang disampaikan dikelas merupakan keterampilan dalam kosa kata (word) dan pelafalan (pronounciation) dan ada juga beberapa games yang dibuat selama pembelajaran berlangsung agar siswa pun dapat memahami dengan cepat. 


\section{Bidang Ekonomi}

Market Day, Program market day sangat efektif dalam menumbuhkan jiwa kewirausahaan siswa yang mengikuti, dengan keterampilan berwirausaha yang dipraktikan dan pelaksanaan kegiatan tersebut mampu mengasah ranah kognitif, afektif, dan psikomotorik.

Menabung Sejak Dini, Program menabung sejak dini ini mendapatkan banyak manfaat hal yang positif karna menabung adalah salah satu cara menghindari dari sifat boros atau konsumtif, menabung bisa menjadikan investasi kita di masa depan dan pelaksanaan kegiatan tersebut mampu mengasah rahan kognitif, efektif, dan psikomotorik.

Penyuluhan Kewirausahaan, Program penyuluhan kewirausahaan sangat efektif dalam menumbuhkan jiwa kewirausahaan dan juga warga yang antusias untuk mulai mengolah hasil pertaniannya menjadi produk olahan untuk dijual yang memiliki nilai ekonomi lebih tinggi.

\section{Bidang Teknik}

a. Pembuatan Rambu "Petunjuk Tempat Peribadatan Masjid Nurul Huda"

Diharapkan warga menjaga plang yang sudah di buat dengan cara pengecatan ulang apabila cat sudah terkelupas dan perhatian besar perawatan ditujukan di coran yang ditanam di tanah agar plang makin kuat dan tidak membahayakan anak sekolah, pengguna jalan dan warga sekitar.

b. Pembuatan Rambu Peringatan "Hatihati Banyak Anak-anak" di SDN Cinangka 04

Dalam rencana program kerja pembuatan rambu peringatan jalan ini diharapkan masyarakat sadar akan keselamatan anak-anak dan pengendara roda 2 maunpun roda 4 warga desa cinangka.

c. Pembuatan Rambu Peringatan "Hatihati Tikungan Tajam!"

Dengan dibuatakannya rambu peringatan, diharapkan dapat memperkecil kemungkinan terjadinya kecelakaan pada tikungan tersebut. Sehingga dapat membuat kenyamanan dan keamanan bagi masyarakat sekitar tikungan.

d. Sosialisasi penerapan E-Commerce pada pemuda setempat

Program Penyuluhan E-Commerce merupakan kegiatan pemahaman tentang jenis perdanganan baru kepada masyarakat desa cinangka dimana pentingnya E-Commerce dalam perkembangan jenis perdagangan yang disebabkan perkembangan teknologi yang meningkat pesat.

\section{Bidang Kesehatan}

a. Penyuluhan dan praktik PHBS di Desa Cinangka

Kegiatan ini bertujuan untuk menyadarkan ibu usia produktif bahwa pentingnya senam bagi ibu dengan cara mengikuti senam sehat secara dini dan rutin di setiap minggunya di Desa Cinangka, Kelurahan Ciampea.

\section{Bidang Agama}

a. Praktik Mengajar PAI di SDN Cinangka 04 Praktek mengajar PAI dilakukan untuk memberikan pembelajaran yang berbeda dan menyenangkan bagi siswa, sehingga siswa dapat mudah mengingat dan melafalkan surat Al-Falaq dengan baik dan benar.

b. Mengajar PAI yang menyenangkan di SDN Cinangka 04

Alasan kegiatan dilakukan untuk memberikan pembelajaran yang berbeda dan menyenangkan bagi siswa, sehingga siswa dapat mudah mengingat 
dan melafalkan Surat Al-Falaq dengan baik dan benar.

c. Penyuluhan ZIS dan Pelarangan Riba di tingkat SD

Program Penyuluhan Kesadaran Perilaku ZIS dan Bahaya Riba sangat efektif dalam menumbuhkan jiwa sosial dan memperdalam ilmu agama siswa/i yang mengikuti.

d. BTQ (Rumah Pintar)

Dalam program BTQ (Baca Tulis Qur'an) yang di dalamnya anak diajarkan membaca Al-Qur'an dengan baik dan benar, disamping belajar membaca Al-Qur'an anak-anak juga diajarkan berbagai ilmu tambahan seperti belajar ilmu tajwid, ilmu fiqih, sejarah islam, dan juga aqidah akhlak.
Bidang Sosial

a. Pelaksanaan lomba 17 Agustus

Dengan mengadakan kegiatan 17 Agustusan di Desa Cinangka agar warga setempat sebagai Warga negara untuk terus mensyukuri nikmat tersebut. Kemerdekaan sejatinya telah menjadi jembatan emas bagi bangsa Indonesia untuk mewujudkan cita-citanya.

b. Pemberian Bibit Pohon pada setiap RT di RW 03 Desa Cinangka

Tujuan dari program pemberian bibit ini agar masyarakat lebih peduli dan berperan aktif dalam upaya penghijauan guna mengurangi pemanasan global, mengurangi polusi udara dan mencegah terjadinya banjir. 


\section{REFERENSI}

Departemen Pendidikan Nasional Dirjen

Dikdasmen Dikmenum, 2002,

Pedoman Pengembangan

Pendidikan Nasional, Jakarta.

An-Nawawi, Maktabah (Penterjermah). 2018. At-Tibyan Adab Penghafal AlQur'an. Sukoharjo: Penerbit AlQowam.

http://irvansyahfa.blogspot.com/2013/03/p engertian-dan-fungsi-al-quran-

dan.html (8 September 2018 20:48pm)

http://kumpulantugassekolahdankuliah.blo gspot.com/2015/01/karakteristikmata- pelajaran-pai.html

September 2018 21:02pm)

Kemendikbud. 2014. Pendidikan Agama Islam dan Budi Pekerti Kelas IV. Jakarta: Kemendikbud.

https://id.wikibooks.org/wiki/Rekayasa_La lu_Lintas/Perambuan_lalu_lintas\#Pe nemp atan_Rambu_Peringatan (10 September 2018 14:04pm)

Takdir, Dedy \& AS, H. Muhammad (2015). Kewirausahaan. Penerbit Winajaya Mahadani Karya: Yogyakarta. www.acadeia.edu

"Kewirausahaan". Wikipedia.06 Septeber 2018. 09 Septeber 2018.
http://id.wikipedia.org/wiki/Kewira usahaan

Gamming, JK. 2016 .Teknik Pengelasan Yang Baik Dan Benar. (Online) http://www.wirasejati.com/teknikpengelasan-yang-baik-danbenar.aspx (Diakses September 2018).

Nursamsi, A. (2014). Dalam Skripsi, Manajemen Penghimpunan Dana ZIS Pada Badan Amil Zakat Nasional (BAZNAS) UIN Syarif Hidayatulah.

17 Agustus Hari Kemerdekaan Indonesia. 11 September 2018 10:31pm. https://id.m.wikipedia.org/wiki/17

\section{Agustus}

Anaswir dan Basyirudin Usman. 2002, Media Pembelajaran. Jakarta: Ciputat Press.

Warsita, Bambang. 2008, Teknologi Pembelajaran: Landasan dan Aplikasinya, Jakarta: Rineke Cipta

Deni, Arsiandi. 2011 Manfaat Penggunaan Video Sebagai Media Pembelajaran. http://arisandi.com/manfaatpenggunaan-video-sebagai-mediapembelajaran/. Diakses 11 September 2018 09:08pm. 